BÁH

Dirección de Ignacio Arellano,

con la colaboración de Christoph Strosetzki y Marc Vitse Secretario ejecutivo: Juan Manuel Escudero
LA LITERATURA EN LA ÉPOCA DE LOS REYES CATÓLICOS

NICASIO SALVADOR MIGUEL CRISTINA MOYA GARCÍA

(EDS.) 


\section{LA EDUCACIÓN DE FERNANDO DE ARAGÓN, DUQUE DE CALABRIA, DURANTE SU INFANCIA Y JUVENTUD (1488-1502) *}

Santiago López-Ríos

Universidad Complutense de Madrid

Para Ángel Gómez Moreno

Fernando de Aragón (1488-1550), el primogénito de Federico de Nápoles e Isabel del Balzo, ha sido sobre todo estudiado como virrey de Valencia, donde desempeñó un importante papel en la política del reinado de Carlos $\mathrm{V}$ y destacó por el decidido impulso con el que favoreció a las artes y las letras en su corte. Si bien es cierto que aún carecemos de una monografia de la etapa valenciana del duque de Calabria, contamos con numerosos trabajos sobre aspectos concretos que nos permiten reconstruir su fundamental aportación al Renacimiento español siendo Virrey, cargo al que accede en 1526, al casarse con Germana de Foix, viuda de Fernando el Católico. Como es de sobra conocido, el duque de Calabria apoyó en Valencia una capilla musical, que llegaría a ser muy reconocida, y en su corte tuvieron lugar fastuosas fiestas y espectáculos teatrales, de los que dejó constancia Luis Milán en su Cortesano (1561). Consumado bibliófilo, preservó una gran parte de la real biblioteca de Nápoles, y acrecentándola con nuevas adquisiciones, consiguió formar una de las grandes colecciones librarias del

* Este trabajo se enmarca en el Proyecto de Investigación del Ministerio de Educación y Ciencia con referencia HUM2004-02841/FILO, dirigido por el profesor Nicasio Salvador Miguel (Universidad Complutense de Madrid). Agradezco también a los profesores Dominique de Courcelles y Gennaro Toscano el apoyo prestado durante mi estancia de investigación en Francia. 
Renacimiento, parcialmente preservada hoy en la Universidad de Valencia. Pocos años después de enviudar (Germana de Foix falleció en 1536), el duque de Calabria contrajo segundas nupcias. El 13 de enero de 1541 se casó con Mencía de Mendoza, viuda de Enrique de Nassau, una mujer muy culta que había tenido a Luis Vives como tutor. Fernando de Aragón murió en 1550, sin descendencia de ninguna de sus dos esposas. Sus funerales tuvieron gran solemnidad y su fallecimiento fue hondamente sentido en Valencia: "no deseo vivir, si no para hartarme de llorar la pérdida y falta que hace en el reino el buen duque de Calabria», se escribió en una crónica de la época ${ }^{1}$.

El objetivo fundamental de este trabajo se centra en un período de la vida del duque de Calabria al que no se le ha prestado aún la atención necesaria: a saber, su infancia y juventud en el reino napolitano, desde su nacimiento en 1488 hasta que, hecho prisionero por el Gran Capitán, se le traslada a España, a la corte de los Reyes Católicos, en 1502. Resulta bastante complicado, por ausencia de noticias, reconstruir con gran precisión la trayectoria del duque de Calabria durante sus primeros catorce años, pero los datos que conservamos sí permiten extraer la conclusión fundamental que expongo en este trabajo. Aunque el duque de Calabria llegó muy joven a la Península Ibérica y nunca volvería a tierras italianas, la educación que recibió en el reino de Nápoles resulta clave para entender sus amplios intereses culturales, que le llevarian a desarrollar una labor de mecenazgo siendo virrey de Valencia sin parangón en la España renacentista.

El profesor Nicasio Salvador Miguel ha resaltado, con el tino que le caracteriza, la importancia de valorar en su justa medida la educación infantil y juvenil y el contexto de los primeros años de la vida de un gobernante para poder entender su posterior mecenazgo cultural. Su conclusión principal, que se resume en su afirmación de que "Isabel [la Católica] muestra también una capacidad de iniciativa cultural que sólo cabe explanar como el fruto de una educación muy completa recibida en los años anteriores $»^{2}$, salvando las lógicas distancias, cabe extrapolarla para el caso de Fernando de Aragón.

' Para una semblanza biográfica de Fernando de Aragón con bibliografia ac tualizada, véase mi entrada sobre este personaje en el Diccionario biográfico español, en prensa.

${ }^{2}$ Salvador Miguel, 2004, p. 122. Para una perspectiva más amplia, ver Echevarría Arsuaga, 2004, pp. 127-153.
El primogénito de Federico (o Fadrique) y de su segunda esposa, Isabel del Balzo, los últimos reyes de la dinastía aragonesa de Nápoles, nació el 15 de diciembre de 1488 en Andria (Apulia). Su infancia y juventud transcurrieron, por tanto, en los reinados de Ferrante (muere en 1494), Alfonso II (que reina entre 1494 y 1495), Fernando II (que reina entre 1495 y 1496) y el de su padre, Federico, que ocupó el trono entre 1496 y 1501, fecha en que Francia y España conquistan el reino. En el refinado ambiente de la corte de Nápoles, se le inculcó a Fernando un amor por la cultura y por los libros que le acompañaría siempre.

A] margen del indiscutible papel de Federico de Aragón en la educación infantil y juvenil de su primogénito, sería injusto desdeñar el que debió de desempeñar su madre, al lado de quien, en Apulia, permaneció stis primeros años hasta ser proclamado duque de Calabria en 1496. Isabel del Balzo, nacida en 1465, pertenecía a una de las grandes familias nobles del reino de Nápoles. Era hija de Pirro del Balzo, príncipe de Aliamura, de quien heredó este título junto con el de duquesa de Andria $^{3}$. Algunos datos interesantes para conocer el tipo de educación que recibió Fernando de Aragón los encontramos en Lo Balzino, un poema sobre su madre en italiano escrito por Rogeri de Pacienza di Nardò ${ }^{4}$. Este poema, probablemente compuesto en 1498, y escrito en octavas, está dividido en ocho libros y dedicado a Antonia del Balzo, la hermana de Isabel. Del autor sólo nos consta que era natural de Apulia y que perteneció al séquito de la reina ${ }^{5}$. Lo Balzino, que se ocupa de las vicisitudes de la vida de Isabel desde su nacimiento hasta 1498, indica, por ejemplo, que en una ocasión Fernando respondió a una pregunta citando un verso de la Eneida (Lo Balzino, lib. II, v. 56) y reproduce un discurso en latín que pronunció en presencia de su padre en 1497 ( $L_{0}$ Balzino, lib. VIII, p. 273). A pesar de que son anécdotas que no pode-

${ }^{3}$ Fodale, 2004, pp. 623-625. Sobre la vida de Isabel del Balzo en Apulia ver Silvestre Baffi, 1973, pp. 320-351.

${ }^{4}$ Mario Marti ed., 1977, pp. 53-280. Sobre Lo Balzino y su autor, además de la Introducción de Marti, 1977, pp. 11-50, se puede consultar el antiguo trabajo de Croce, 1897, pp. 632-701. Más reciente es el trabajo de Holtus, 1991, pp. 6578.

${ }^{5}$ Aparte de Lo Balzino, Rogeri de Pacienza también escribió un Triunfo en terza rima elogiando a Isabel, conservado en el mismo manuscrito (Perugia, Biblioteca Comunale, ms. F 27) (Marti, ed., 1977, pp. 283-306) 
mos entender al pie de la letra, revelan que Fernando recibió en Italia el tipo de educación propia de un príncipe.

Por su pertenencia a una de las grandes familias nobles napolitanas, Isabel del Balzo, incluso antes de ser reina, acostumbraba a tratar con los intelectuales y los personajes más preeminentes. De hecho, por ejemplo, la noticia de su boda con Federico de Aragón la recibió de Giovan Battista Caracciolo, entonces ayudante de cámara de Alfonso, duque de Calabria, quien se desplazó de Nápoles a Andria sólo por este motivo ${ }^{6}$. Aparte de un estrecho vinculo con Jacopo Sannazaro, al que me referiré más adelante, hemos de recordar la mutua admiración y estima que mantuvieron el humanista Mario Equicola e Isabel del Balzo a lo largo de toda su vida. Aunque a Mario Equicola se le conoce, sobre todo, porque acabó siendo el tutor y secretario de Isabel d'Este, empezó su carrera como intelectual en el Sur de Italia, cerca de Isabel del Balzo. Lo Balzino cuenta, por ejemplo, cómo el humanista recitó un poema en latín en honor de Isabel y su hijo Fernando en Barletta en 1496 (Lo Balzino, lib. VI, vv. 943-980). El poema de Equicola es un diálogo entre Apolo, quien reconoce sentir envidia de Isabel por su fama, y Júpiter, quien refuta sus argumentos y exalta tanto a Isabel como a su primogénito ${ }^{7}$

Si queremos profundizar en el papel de Isabel del Balzo en la educación de su primogénito, hemos de recurrir a noticias indirectas y cronológicamente un poco posteriores, si bien no por ello menos significativas. Un muy valioso testimonio del interés de la reina Isabel del Balzo en la formación humanística de sus descendientes se halla en las cartas por ella escritas sobre el profesor de griego del infante César de Aragón, el hermano menor de Fernando, asunto del que me he ocupado en otro trabajo. César, que había nacido en 1501, poco tiempo antes de la caída del reino, acompañó a su madre en su exilio en Ferrara, donde recibió clases de griego del humanista Marco Antonio Antimaco. La alta estima que profesaba Isabel del Balzo por el tutor de su hijo está patente en una serie de cartas que escribe, entre 1517 y 1519 , a Mantua, pidiendo a los Gonzaga que accedan a las peticiones sobre un asunto de herencia que preocupaba al humanista. De esta correspondencia, conservada hoy en el Archivio Gonzaga

${ }^{6}$ Volpicella, ed., 1916, p. 236.

${ }^{7}$ Marci, 1981, pp. 1319-1328 y Kolsky, 1991, pp. 48-49. en Mantua, importa destacar que la reina se deshace en elogios hacia Antímaco, por la labor que ha realizado con el joven César, el cual, por otro lado, sabemos que solicitaba manuscritos en griego a Isabel d'Este, indicio claro de que llegó a dominar esa lengua ${ }^{8}$.

$\mathrm{Si}$ bien se trata de noticias relativas al hermano pequeño de Fernando durante su exilio en Ferrara, hemos de suponer que Isabel del Balzo tendría idéntico interés (si no mayor) por conseguir una sólida e lucación humanística para su primogénito, especialmente desde que $* n 1496$ éste se convierte en heredero del trono. Asimismo, debemos subrayar que esta mujer comprendía el inmenso valor de la bibliote a real de Nápoles y que su amor por los libros influyó, al igual que $\epsilon$ ! de su marido, en la bibliofilia de su hijo. A la muerte de su esposo, ocurrida en Tours en 1504, Isabel se convierte en la heredera de una cie las mayores y mejores bibliotecas del Renacimiento italiano, $y$, a partir de entonces, puso especial celo en preservar los valiosos volúmenes regios y en evitar su dispersión. Es cierto que, durante su exilio en Ferrara, Isabel vendió algunos libros, pero esto lo hizo por razones de extrema necesidad. Además, lo significativo es que logró preseivar el grueso de la colección real, que terminó pasando a su heredero, una vez establecido éste en Valencia como Virrey9.

Desde 1495, la educación del joven Fernando se confia a Crisóstomo Colonna da Caggiano (ca. 1457-ca. 1539), un humanista muy cercano a Giovanni Pontano y tutor también del padre del duque ${ }^{10}$. Colonna le instruyó en la lengua latina y, en general, en los estudios clásicos, como recordará Gonzalo Fernández de Oviedo: «El Duque en su pueriçia tuuo vn secretario y maestro docto llamado Miçer Chrysóstomo, y éste le enseñó la lengua latina» escribirá el cronista español en sus Batallas $y$ Quinquagenas ${ }^{11}$. Además, sabemos que Colonna preparó para don Fernando una traducción italiana del Strategikós del filósofo griego Onasandro, un tratado sobre los deberes del general ${ }^{12}$.

${ }^{8}$ López-Ríos, 2002, pp. 201-243, esp. pp. 205-206.

${ }^{y}$ López-Ríos, 2002.

11) Sobre Colonna desgraciadamente no he podido consultar Augelluzzi, 1856 ni Altamura, 1956, pp. 171-183. Bibliografía más reciente hay en Vecce y Tordeur eds., 1993, p. 52, n. 1. Hay breves referencias a Crisóstomo Colonna en la poesía de Benet Garret. Ver Parenti, 1993, pp. 44 y 100.

"Fernández de Oviedo, Batallas y Quinquágenas, p. 138.

${ }^{12}$ Berlín, Deutsche Staatsbibliothek, Ms. Hamilton 466. Ver Vecce y Tourdeur eds., 1993, p. 52. n. 2. 
En la corte de Isabel del Balzo en Apulia, y más tarde en Nápoles, el joven Fernando debió de empezar a desarrollar un gusto por las farsas y espectáculos teatrales, que impulsaría de forma decisiva siendo Virrey en Valencia. Lo Balzino detalla que, en los desplazamientos de Isabel del Balzo por Apulia, se le recibia con distintos festejos en las ciudades por las que pasaba ${ }^{13}$. En consonancia con la costumbre napolitana, arraigada en el Reino desde los tiempos del Magnánimo, de celebrar espectáculos teatrales de gran aparato, Jacopo Sannazaro, un intelectual muy cercano a la familia real (escribiría una égloga Proteus sobre la marcha del Duque de Calabria a España y acompañó a Federico en su exilio en Francia [Vecce, 1988a]), compuso dos farsas para festejar la conquista de Granada por los Reyes Católicos. De estas obras, tituladas La presa di Granata y Il trionfo della fama, no sólo conservamos los textos, sino también detalles sobre la representación por una carta que el propio poeta escribió a Isabel del Balzo. En la segunda de las citadas, representada el 6 de marzo de 1492, durante el Carnaval, en los propios aposentos de Federico de Aragón en Nápoles, la Fama se situaba en un carro que tiraban elefantes, guiados, a su vez, por gigantes, cortejo que entró en el comedor atravesando un arco triunfal. La pieza concluía con himnos celebrando la conquista de la plaza musulmana y a los monarcas españoles y napolitanos ${ }^{14}$. $\mathrm{La}$ carta de Jacopo Sannazaro a la Princesa de Altamura demuestra la comunicación constante que había entre el entorno de Federico y su segunda mujer, residente en Apulia hasta que su marido fue proclamado rey. A pesar de que sus responsabilidades políticas y militares le impidieron residir con su esposa los primeros años de matrimonio, la visitó con frecuencia y no se desentendió, ni mucho menos, de la formación de su primogénito ${ }^{15}$.

Federico de Aragón, notable mecenas, consumado bibliófilo, y un hombre de amplia cultura, había tenido como tutor en su juventud, entre otros, al humanista y gran poeta en latín Elisio Calenzio, miembro de la Academia Pontaniana ${ }^{16}$. El último rey aragonés de Nápoles,

${ }^{13}$ Ver comentarios a estos pasajes de Lo Balzino en Silvestri Baffi, 1973.

${ }^{14}$ Sannazaro, 1961, pp. 276-295. Sobre este asunto ver Fernández Murga, 1959, p.186; Boillet, 1987, pp. 233-256 y Maxell Snyder, 1996, pp. 41-62.

is Silvestre Baffi, 1973, p. 329

${ }^{16}$ Croce, 1925, pp. 7-28. Sobre Federico de Nápoles ver Volpicella, 1908 Volpicella, ed. 1916, pp. 234-241 y Dizionario biografico degli italiani, pp. 668-682. "quello che in scienza non trova paro", según una crónica de la épo$\mathrm{Ca}^{17}$, con certeza también fomentaría que su hijo estudiara a los clásicos, como él mismo hacía. En un gesto que recuerda a las anécdotas que circulaban sobre su abuelo Alfonso V el Magnánimo, Federico, por ejemplo, pidió a Jacopo Sannazaro, a través de Benet Garret, que examinara un manuscrito de Virgilio, para comentarlo al día siguiente con é $\mathrm{l}^{18}$. La estrecha amistad entre Federico y Sannazaro, testimonio ca la indudable inclinación del monarca por los estudios clásicos, la de..ribió con certeras palabras Percopo:

nome del Sannazaro resterà eternamente congiunto a quello di don Fe derico. Un simile esempio di tanta amicizia e fedeltà, anche nell'avversa fortuna, fra un principe e un poeta, non credo che registri la stori... Quelle due anime erano fatte per intendersi. Franca, schietta, affetuosa quella di Sannazaro; gentile, generosa, magnanima quella di don Federico ${ }^{19}$

Por otro lado, el último soberano aragonés de Nápoles desarrolló una verdadera pasión por la poesía en vernáculo como pone de manifiesto no sólo su apoyo al circulo petrarquista en su reino, que incluía a Giovanni Pontano, Jacopo Sannazaro, Benet Garret, Giuliano Perleoini y Giovan Francesco Caracciolo, sino también la correspondencia que mantuvo sobre el asunto con Lorenzo de Medici, con quien se llegó a encontrar en Pisa en 1476 para tratar de su común afición. A raíz de ese encuentro, surgió la llamada Raccolta aragonese, una antología de poesía en toscano compilada por Lorenzo como regalo a Federico para conmemorar dicha reunión ${ }^{20}$.

Aparte de que el futuro duque de Calabria se enriqueciera con el trato de los intelectuales del entorno de su padre, Federico debió de

${ }^{17}$ Luigi Volpicella, 1916, p. 4.

${ }^{16}$ Percopo, 1892, p. CCXCI, apud Carol Kidwell, 1993, p. 221. Sobre Benet Garret, Parenti, 1993.

${ }_{19}$ Percopo, 1886, pp. 318-321, citado por Silvestre Baffi, 1973, p. 347.Volpicella recuerda los elogios que recibió Federico de Aragón de grandes escritores: «Lo lodarono i contemporanei, Pontano, Galateo, Comines, Chariteo, Poliziano e poi il Porzio; Rustico Perleoni gli dedicò il suo Perleonio. Ver Volpicella, ed., 1916 p. 240. Más información sobre las relaciones de Federico de Nápoles con escritores de su tiempo en De Marinis, 1952, pp. 121-122.

${ }^{20}$ Ver Santero, 1988, p. 310; Parenti, 1993, pp. 39-40, y Schwartz, 2001, p. 253. 
transmitir, asimismo, a su hijo su bibliofilia, y cabe pensar que inculcó en él la conciencia del valor simbólico y patrimonial de la real biblioteca de Nápoles. Federico, incapaz de conjurar las amenazas que se cernían sobre un reino a punto de sucumbir ante los ejércitos de Francia y España, y aunque en su breve reinado no tuvo la oportunidad de desarrollar un mecenazgo de miniaturistas semejante al de sus predecesores, mostró una enorme sensibilidad en la conservación de la gran biblioteca que había empezado a reunir Alfonso el Magnánimo en Castelnuovo ${ }^{21}$. De hecho, cuando, en 1501, Nápoles cae ante los ejércitos de Luis XII y Fernando el Católico, Federico se llevó consigo toda la colección real, primero a la isla de Ischia y luego a Francia, consciente de su importancia cultural y valor simbólico de los valiosos códices. El hecho de que se realizara un detallado inventario de la biblioteca en Ischia, hoy desgraciadamente desaparecido, y de que fuera de Castelnuovo hubiera personal encargado de ella prueba la gran estima que, incluso en circunstancias excepcionalmente dificiles, tenía Federico de Aragón por sus libros ${ }^{22}$. Sólo por razones de extrema necesidad se vio forzado a vender algunos volúmenes durante su exilio en Francia al cardenal Georges d'Amboise ${ }^{23}$.

Mención aparte merece la educación musical que Fernando de Aragón recibiría durante su infancia y juventud, primero en Apulia y, después en la capital del reino, reconstruible a grandes rasgos por noticias indirectas. Durante su vida en Italia, Don Fernando tuvo que estar expuesto al exquisito ambiente musical que tanto habia impulsado su abuelo Ferrante. Roberta Schwartz, en su reciente tesis doctoral sobre el mecenazgo musical en las cortes nobiliarias españolas, recuerda que, entre los genios de la música activos en Napoles en ese momento, se encontraban Johannes de Tinctoris (1445-1511) y Benet Garret, pero la corte también recibía las visitas de figuras como Serafino dall'Aquila, Francisco Gaffurius y Alexander Agricola ${ }^{24}$. Este amor por

${ }^{21}$ Ver De Marinis, 1952, pp. 119-121, D’Urso, 1998, p. 299.

${ }^{22}$ Santoro, 1988 , p. 202

${ }^{23}$ Toscano, 1999, pp. 275-300.

24 "According to Atlas, Tinctoris' association with the court had ended by 1491 , and therefore probably had no direct impact on the young Don Fernando; nonetheless, his long residence in Naples and his writings for the royal library likely made him an important influence in the young duke's musical education. The same likely applied to Gaffurius, who was in exile in Naples with the Doge la música que adquirió en Nápoles, se convirtió en una afición que le acompañaria toda su vida, y explica, en definitiva, la gran labor de mecenazgo que en este terreno desarrolló siendo virrey en Valencia. Como recordará Gonzalo Fernández de Oviedo,

Y de su natural fue estudioso e amigo de libros e muy parçial a la músira, e la entendía muy bien, y fue muy afiçionado a la caça. Y así en esta tres cosas muy inclinado, tenía e trahía consigo una librería grande, e $\mathrm{m}$ ichos halcones e caçadores, e vna copiosa capilla de muchos buenos cantores, e en estas tres cosas gastó mucho e muy hordinario ${ }^{25}$

E. suma, el tormentoso clima político del reino de Nápoles a finales del siglo xv no constituyó un impedimento para que este joven que terminaría convirtiéndose en el heredero del trono recibiera una esmerada educación, supervisada y fomentada por sus padres.

Pero la corte de los Trastámaras napolitanos se distinguía por su multiculturalidad y plurilingüismo. En su infancia y juventud, el duque de Calabria aprendería el toscano y el napolitano, el latín como lengua de cultura, y estaría también expuesto a otras lenguas, como el francés (que se hablaba con frecuencia en el entorno de Federico de Aragón, cuya primera mujer había sido frances ${ }^{26}$ ), el catalán, el aragonés y muy especialmente, por supuesto, el castellano, el cual - podemos especular- hablaría antes de llegar a la Península Ibérica en 1502. No olvidemos que los primeros seis años de vida de Fernando de Aragón transcurrieron en el reinado de Ferrante, quien empleaba el castellano en su círculo familiar ${ }^{27}$. Un códice redactado en esta lengua, perteneciente a la biblioteca de Ferrante y que heredo Federico, demuestra el vivo interés de los monarcas napolitanos en asuntos hispánicos. Me refiero al ms. Esp. 110 de la Biblioteca Nacional de Francia, un compendio en español de historia de Castilla especificamente preparado para el rey Ferrante. En la dedicatoria de esta obra

of Genoa from 1478 to the late 1480 ss. Ver Schwartz, 2001, p. 253. Cf. también Anglés, $1960^{2}$, pp. $18-25$.

${ }^{25}$ Gonzalo Fernández de Oviedo, Batallas $\gamma$ Quinquagenas, p. 138

${ }^{26}$ Un viajero extranjero en Nápoles escribió en 1488: "Alla corte di Don Federigo si parlava francese, giacchè la maggior parte delle persone erano dei paesi oltramontani, com'era stata la prima consorte del principe*. Ver Volpicella, ed., 1916, p. 238.

${ }_{27}$ Sobre el 'españolismo' de Ferrante, ver Croce, 1949, p. 60. 
se declara la conveniencia de que el monarca tenga "perfetta notiçia de sus raýzes", pero presentada de una forma sumaria, dado el poco tiempo del que dispone, y lo "prolixas (...), trabajosas y enoj osas de leen que son las crónicas castellanas ${ }^{28}$. La cultura hispánica en $\Gamma$ Nápoles en el último tercio del siglo xv carecía del mismo peso que en la época del Magnánimo o en la primera etapa del reinado de su hijo, pero aun asi las relaciones culturales y políticas entre la Italia meridional y la Peninsula Ibérica se encontraban plenamente vigentes.

A travês de la viuda de Ferrante, la reina Juana de Nápoles, el joven príncipe tendría acceso también a la cultura hispánica. $L^{\text {as rela- }}$ ciones entre la hermana de Fernando el Católico y los últimos soberanos aragoneses de Nápoles, aunque tirantes, fueron, co ${ }^{\mathfrak{n}}$ todo, estrechas. Federico entregó la Lugartenencia del Reino a Juana cuando tuvo que ausentarse para sofocar el levantamiento del Príncipe de Salerno y mantuvo una fluida correspondencia con ella. La reina Juana llegó a proponerle el matrimonio de Fernando de Aragón con su hija, idea que desechó el rey asegurando que los enlaces entre parier ttes daban malos resultados ${ }^{29}$. Entre 1497, fecha en que Isabel del Balzo llega a Nápoles, y 1499, en que la hermana del Católico se traslada a España, estas mujeres vivieron una temporada juntas en Casteln ${ }^{\text {uovo }}{ }^{30}$, periodo en el que cabe especular que el Duque de Calabria llegaria a conocer bien a la viuda de Ferrante y a su hija. Estas dos mujeres fueron, sin duda, el principal y más directo nexo entre los Reyes Católicos y Federico e Isabel del Balzo. Diversas cartas de las reinas Juanas a Juan II de Aragón, a Fernando el Católico y a Iśabel la Católica, preservadas en el manuscrito Esp. 318 de la Biblioteca Nacional de Francia, evidencian un constante contacto entre ambas casas reinantes. Entre los españoles cercanos a Fernando de Aragón en el reino de Nápoles, destaca asimismo Gonzalo Fernández de Oviedo, el cual entra al servicio del rey Federico en $1500^{31}$. Esa proximidad de Oviedo al duque se acentuó, a partir del traslado a España del he-

${ }^{28}$ Comp. Alfred Morel-Fatio, 1892, núm. 134; Jardin, 1991, pp. 117-126; Garcia y Jardin, 1996, pp. 77-94; y Jardin, 2000, p. 145, n. 16.

${ }^{29}$ Croce, 1894, pp. 354-375; Fernández Murga, 1959, pp. 175-196, pp. 186 187; Torre, 1959, pp. 245-248; Martínez Ortiz, 1984, pp. 37-60.

${ }^{30}$ Silvestre Baffi, 1973, p. 344

${ }^{31}$ Ver, aun cuando no son buenas biografias, Ballesteros Gaibrois, 1958, pp. 1317, y Ballesteros Gaibrois, 1981, pp. 65-66. redero del trono de Nápoles en 1502. Desde esa fecha hasta 1512, el futuro cronista de Indias está al servicio del duque de Calabtia, por decisión de Fernando el Católico. El cariño profesado por Oviedo al joven príncipe explana que el escritor le dedicase, durante la prisión del duque en Játiva, su novela de caballerías Claribalte ${ }^{32}$. Asimismo, lo recordará con mucho afecto, años más tarde, en sus Batallas $y$ Quinquagenas, en cuyo manuscrito autógrafo el único escudo de armas qu.e reproduce es, precisamente, el de Don Fernando ${ }^{33}$.

La conquista de Nápoles por Francia y España, que obligó aì duque de Calabria a separarse de su familia, interrumpió también bruscamen ce su formación humanística. Federico de Nápoles apenas pudo oponei resistencia a la invasión del reino. Después de la caída de Capua se vio forzado a firmar la tregua de Aversa (25 de julio de 1501) en la que entregaba el control de la capital a los franceses, quienes le permitian permanecer en Ischia unos meses (Volpicella, 1908 p. 65). En agosto el rey abandonó la capital y se refugió con su mujer y sus hijos más jóvenes en esta pequeña isla, desde donde pasarían a Francia (Capasso ed., 1876, p. 67; Passero, 1785, p. 127) ${ }^{34}$. Mientras, el duque de Calabria defiende la plaza de Tarento frente al Gran Capitán. Éste, por lo visto, engañándole con la falsa promesa de garantizarle, tras su rendición, la libertad de dirigirse a donde quisiera, consiguió que se entregara ${ }^{35}$. Con el traslado a la corte de los Reyes Católicos en 1502, comienza una nueva etapa de la vida del duque de Calabria, de la que espero ocuparme en detalle en otra ocasión. Sirva ahora sólo señalar que, si bien Crisóstomo Colonna acompañó al duque de Calabria a España, en donde permanecería hasta 1506 , fecha en la que el humanista regresa a Nápoles y entra al servicio de Isabel de Aragón, duquesa de Bari y viuda de Giangaleazzo Sforza, por encargo de la cual hizo un viaje a la Península Ibérica en 1516,

${ }^{32}$ Fernándex de Oviedo, Claribalte.

${ }^{33}$ Fernánde $\chi$ de Oviedo, Batallas $\gamma$ Quinquagenas, p. 141.

${ }^{34}$ La caída de Nápoles, el traslado a Ischia y la posterior salida para Francia del rey Federico, mientras Isabel permanece en la isla se narra también en Auton, 1889-1895, cap. XV, pp. 76-91. Isabel del Balzo, aunque en septiembre de 1501 había partido a Francia, regresó al poco tiempo a Ischia para seguir de cerca el destino de su hijo asediado en Tarento. Una vez que cayó esta plaza, se trasladó definitivamente a Francia. Ver Volpicella, ed., 1916, p. 239.

${ }^{35}$ Castañed $_{a}, 1911$, p. 270, y Ruiz-Domènech, 2002, pp. 329-330. 
la formación que el joven príncipe recibiría en la corte de los Reyes Católicos fue bien distinta a la educación italianta, pues al contexto cultural la combiado por complctor. Así lo sugiere una fascinante obra del humanista Antonio de Ferrariis, conocido como Galateo, titulada De educatione. Este tratado, bien estudjado en su relación con otros textos buminiśsticos, pero desgraciadanenente bistinte desitendi(do contre los hispanistas, se debió de escribir hacia 15015. es decir, despuís de la muerte del rey Federico an su exilio de Tours. En cste libro Galateo se dirige a su gran anigo Crisóstono (Colonna ${ }^{17}$, como tutor del príncipe en su exilio en la Península Ibérica, y reflexiona sobre la educación más apropiada para el duque de Calabria. Sin enubargo, lo que se plantea como un texto pedagógico termina convirtiéndose en un atacue abierto contra la política y la cultura hispánicas de la época de los Reyes Católicos, y ell menor medida también contra las francesas ${ }^{\text {is. }}$. Galatco, quien ya había escrito al duque de Calabria una epístola antes de 151)1, recordandole que les principes debian anteponer sus funciones puiblicas al sus responsabilidades privadas ${ }^{31}$. alberga en el De educintione todavia la esperanza de yue el trono de Nápoles recaiga en su legítimo lecedero. Comicnza haciendo un repaso, lleno de digresiones, sobre los distintos nodelos educativos en diferentes culturas, desck la Antigiicdad al presente, resaltando siempre, por encima de todo, los valores educativos de Grecia y Roma, que, según él, en Italia en ese momento sólo mantiene vivos Venecia, vista como una nueva Atchas (\$36-37. pp. 94-96)). Le exaspera, cn cspecial, el afún español de subrayar que su linaje deriva de los grodos, simbolo para el humamista de barlarie. Así, arremete contra Falbricio Gauberte de Vagad. el monje cisterciense autor de la Corónica de Aragín, a quien contempla como un defensor a ultranza de la ligereza y vinidad hispánicas, frente a la gratitas italiana (\$26-27, pp. 84-81; \$29) p. 88) Le anima a Colonna a que aleje al joven de los juegos de cartas,

3o Desgraciadamente no sabemos prácticamente nadia del paso de este humanista por España. Vecce, 1988 b, p. 327.

i) Gabateo había escrito otras cartas a Colomin. Ver 1)e Ferrariis, 1959, n. X11 (pp. 97-100); 11. XIII (pp. 101-103); n. XVl (pp. 121-123), n. XXV (pp. 1+7-150); 11. XXVIII (pp. 171-172); n. XXIX (pp. 173-17\%).

"sobre esta obra, aparte del estudio introductorio de Vecce en la edicion de Tordeur, ver Zacchino, 1968, pp. 620-6.33, y Vecee. 1988sh,

${ }^{31 .}$ Galateo, 1459. pp. 81-84 de dados. de ajedrez y de azar, que sólo sirven para perder el tiempo (\$69. p. 13(1-132). «La causa de todos los males es la mala educación, el desprecio de las letras y el frecucntar a los peores lombreso ( $\$ 70$,

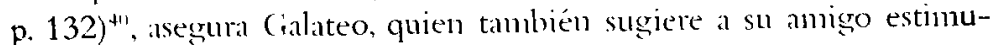
lar en ef duque de Calabria la afición a la caza, sobre todo la caza mayor, por lo gue implica de fortalecimicnto fisico y preparación militar (\$71. p. 1.34). Juzga imprescindible el cultivo de la música, pero siguicndo modeles italianos en hugar de franceses o espanoles (\$7.3) Entre las iecturas clásicas, Homero y Virgilio som preferibles a Propercio y Catulo, y en lenguas vulgares reconienda a Dante y Petrara, micntras que rechaza, en térnumos bastante sarcísticos, a Juan de Mena y a los poetas cancioneriles, de quienes consenta que "al éstos, yo los llamatrí, a la mancra espanola, más bicu 'copleadores'; nosotros buscamos poctas, que sean, como dice Macrobio de Virgilio, muy expertos en todia las disciplinas" entre los españoles, como un entretenumiento bárbaro propio de árabes, y le pide a Colonna que no olvide que su discipulo se ha de ejercitar en la lucha de espada contra espada, lanza contra lanza (\$ 76). En cuanto a la vestimenta, le aconseja que "nuestro adolescente se vista, incluso en medio de España, o como prefieren los españoles, 'Cothia', con vestidos italianos, que no son ni demasiado sobrios ni lujosos: (ute vaval limpio, no reluciente» $(\$ 87)^{+2}$. El núcleo esencial del De 'dumarimo' podria resumirse en el deseo de que Fernando de Aragón continuc educándose a la manera italiana:

Tú, si cres verdideramente aquel a quien yo sicmpre he estimado, Crisostomo, a cste inclito adolescente, al clual has temcio a tul caryol desde su intancia y his cuidado como una nodrizil, edúcalo segriul del modeto italiano. on los bucnos preceptos y costumbers. on las ketras y disciplinas



"1" "Omuium malorum causia est mala educatio, contemptur littcrartun, er pessimorum virorum consuctudem (\$7). p. 132)

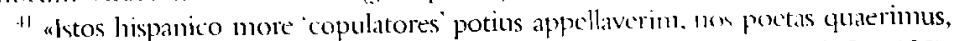

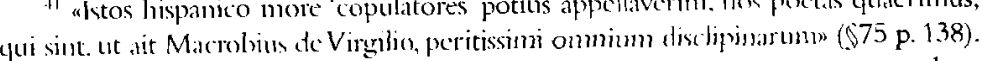
12. "Induat "se igitur noster adolescons, vel in medial 1 hispania, seu, ut malunt Hispani, Ciothia, ifalicis vestibus. quac nec avarae sumt nee prodigae; sit mundus, non mitidus" (S 87. p. 152).

"Tu si is es quem scmper existimavi, Chrysostome, adolescentem inclytum. quem ab infantili accepisti ct ut mutrix fovisti, instruc italica institutione, bonis 
Me gustaría pedirte lo que te he rogado y suplicado ciertamente una y muchas veces: devuélvenos a nuestro joven rey, cuando a los Reyes Católicos les parezca, tal y como lo recibiste. Italiano lo recibiste, devuélvelo italiano; no español. Que aprenda a hablar español y también francés, si quiere, pues es hermoso conocer las lenguas y las costumbres de mucha gente, sin embargo no hasta el punto de anteponer la barbarie de la "algarabía" o la gótica - de lo cual también abominan los mismos españoles- a la Latinidad. Al contrario, entre los suyos que use siempre la lengua maternâ, paĩa que, de la gravedad y simplicidad del italiano, no pase a los sonidos extraños y a los donaires españoles, las agudezas aduladoras, chistes, palabras indecentes. Que aprenda latin, lo cual aconsejan los más sabios de los españoles, aunque aquellos que llaman "galanes" se mofen. $(\$ 52, \text { p. } 112)^{44}$.

Antonio de Ferrariis escribió el De educatione con más de sesenta años, con el sueño un tanto iluso de que Fernando de Aragón recuperara el trono de Nápoles. Su obra nunca se llegó a imprimir y no hay certeza alguna de que circulara por España. Con el regreso de Crisóstomo Colonna a Nápoles en 1506, se cumplieron los peores presagios del Galateo. En realidad, el proceso de 'hispanización' del duque de Calabria era irreversible, como demuestra el hecho de que compusiera lírica cancioneril durante su prisión en Játiva, según nos trasmite, citando incluso el poema, Gonzalo Fernández de Oviedo ${ }^{45}$. Fernando de Aragón ya nunca volvería a Italia y sería en España donde desarrollaría su vida, que pasa a primer plano de la escena política y cultural después de ser rehabilitado por Carlos $V$ y nombrado Virrey de Valencia en 1526. Una conmovedora carta de 1542 que escribe a

praeceptis et moribus, graecis et latinis litteris et disclipinis, non gallicis aut hispanicis" $(\$ 49$, p. 110).

44 "Te vero iterum atque iterum rogatum atque obtestarum velim: redde nobis regulum nostrum, cum sanctissimis regibus visum fuerit, talem qualem accepisti. Italum accepisti, Italum redde, non Hispanum. Discat hipanice loqui, et etiam gallice, si libuerit. Pulchrum est enim multarum gentium ut et mores sic et linguas noscere, non tamen, quod ipsi etiam Hispani abominancur, algaraviam aut gothicam barbariem latinitati anteponat, sed utatur semper inter suos parria lingua, ne ab italici sermonis gravitate simplicitateque transeat in peregrinos sonos et in hispanos lepores, blanditias argutulas, scommata, ledorias. Discat latine, quod Hispaniarum sapientisimi suadent, quamvis ii, quos galanes dicunt, derideant" (\$ 52, p. 112).

${ }^{45}$ Fernández de Oviedo, Batallas y quinquagenas, p. 140.
Ercole II d'Este en perfecto castellano comunicándole la noticia de la muerte de su querida hermana Julia, ilustra hasta qué punto ha llegado su proceso de hispanización. El duque de Calabria prefiere el castellano al italiano para dirigirse a su pariente en Ferrara:

Illustrísimo Señor Sobrino. Ya vuestra Señoría habrá sabido cómo plugn a Dios llevar para sí a la Infante Doña Julia, mi hermana, dexándonos ta.i affligidos y lastimados con su muerte que, si no fuera el tener por c.:- to que según su vida y fin está en el cielo, ninguna otra cosa bastará para nos consolar, según la gran pérdida de su persona, que de verdad p ra mí ha sido de las mayores que en esta vida me podían venir. Pero, c'rmo en ella haya tan poco que confiar, mayormente para persona tan acostumbrada a sus xaraues y tragos amargos como la mía, hállola hecha a las armas y conformada con la voluntad de Dios en todo lo que ansí le plaze, hame parecido dar aviso dello a Vuestra Señoría, por descansar cun él mis trabajos y fatigas sabiendo la parte que dellas le cabrá, como a Señor y verdadero hermano de todos, cuya Illustrísima persona y estado Nuestro Señor guarde y acresciente como dessea. De Valencia, a xvii de março MDXXXXII. De Vuestra Illustrísima Señoria, suo tío amantisimo, el Duca de Calabria ${ }^{46}$.

Aun así, parece claro que la sólida formación italiana, recibida por el duque de Calabria en sus primeros catorce años de vida, contribuyó a moldear su personalidad y su afición a las letras y a las artes e imprimió un carácter único en el mecenazgo cultural que ejerció en España en el segundo tercio del siglo xvi.

\section{BiBliografía}

Altamura, A., Studie e ricerche di letteratura umanistica, Napoli, S. Viti, 1956 ANGís, Augelluzzi, G., Intorno alla vita e alle opere di Grisostomo Coluna da Caggiano, Pontaniano Accademico, Napoli, s.n., 1856

Auton, J. d', Chroniques de Louis XII, ed. M. La Clavière, Paris, Librairie Renouard, H. Laurens, successeur, 1889-1895, vol. II.

${ }^{46}$ Archivio di Stato di Modena, Archivio Segreto Estense, Cancelleria, Carteggi Principi Esteri, b. 1247/3. 
Ballesteros Gaibrois, M., Vida del madrileño Gonzalo Femández de Oviedo $\gamma$ Valdés, Madrid, Instituto de Estudios Madrileños, 1958.

- Gonzalo Femández de Oviedo, Madrid, FUE, 1981.

Bolllet, D., «La participation d'un humaniste aux spectacles de la cour des Aragonais de Naples: les farces de J. Sannazaro", en La fêtte et l'écriture: the atre de cour, cour-theatre en Espagne et Italie 1450-1530, Aix en Provence, Université de Provence, 1987, pp. 233-256.

CAPAsso, B., ed., wLe cronache de li antiqui ri del Regno di Napoli di Gaspare Fuscolillo", Archivio storico per ie province napoletane, 1, 1876, pp. 35-81.

Castañeda, V., «Don Fernando de Aragón, Duque de Calabria. Apuntes biográficos", Revista de Archivos, Bibliotecas y Museos, 25, 1911, pp. 268-286.

Croce, B., "La corte delle tristi regine a Napoli", Archivio storico per le province napoletane, 19, 1894, pp. 354-375.

- "Isabel del Balzo, regina di Napoli, in un inedito poema sincrono", Archivio storico per le province napoletane, 22, 1897, pp. 632-701.

- "Elisio Calenzio", en Varietà di storia letteraria e civile, Bari, G. Laterza, 1925, pp. 7-28.

- Spagna nella vita italiana durante la Rinascenza [1917], Bari, Laterza, 1949.

D'Urso, T., "Federico de Aragón entre Nápoles y Tours», en La biblioteca real de Nápoles en tiempos de la dinastía aragonesa, ed. G. Toscano, Valencia, Generalitat Valenciana, 1998, pp. 299-303.

De Ferrariss, A., Galateo, Epistole, ed. A. Altamura, Lecce, Centro di Studi Salentini, 1959.

De Marinis, T., La biblioteca napoletana dei re d'Aragona, Milán, Ulrico Hoepli Editore, 1947-1952, 4 vols.

- Supplemento, Verona, Stamperia Valdonega, 1969, 2 vols.

Dizionario Biografico degli italiani, Roma, Istituto della Enciclopedia Italiana, 1974

Echevarría Arsuaga, A., «La juventud de los hijos del rey en la Castilla del siglo xV", Mélanges de la Casa de Velázquez. Nouvelle Série, 34.1 (2004), pp. 127-153.

Fernández de Oviedo, G., Batallas $y$ Quinquagenas, ed. J. B. Avalle-Arce, Salamanca, Diputación de Salamanca, 1989.

- Claribalte, ed. A. del Río Nogueras, Alcalá de Henares, Centro de Estudios Cervantinos, 2001.

Fernández Murga, F., «Doña Juana de Aragón, reina de Nápoles», en Studi in onore di $R$. Filangieri, Nápoles, 1959, vol. II, pp. 175-196.

Fodale, S., "Isabella del Balzo", en Dizionario Biografico degli Italiani, vol 62 , Roma, Istituto della Enciclopedia Italiana, 2004, pp. 623-625.

GARcia, M. y J. P. JaRdin, "El didactismo de las sumas de crónicas (s. xv)», Diablotexto. Revista de crítica literaria, 3, 1996, pp. 77-94.
Holtus, G., «Mehrsprachigkeit und Dichten in fremder Sprache: Lo Balzino (1497/1498) von Rogieri di Pacienza di Nardò», en Das zweisprachige Individuum und die Mehrspachigkeit in der Gesellschaft. Wilhem Theodor Elwert zum 85. Geburtstag, ed. G. Holtus y J. Kramer, Stuttgart, Franz Steiner Verlag, 1991, pp. 65-78.

JARDIN, J. P., «Contribution à l'étude des résumés de chroniques castillanes du xv siècle», Atalaya, 1, 1991, pp. 117-126.

- $« 1$ modelo alfonsí ante la revolución trastámara. Los sumarios de crónicas generales del siglo XV", en La historia alfonsi: el modelo $\gamma$ sus destinos (siglos xiii-xv). [Seminario onganizado por la Casa de Velázquez (30 de enero de 1.995)], ed. G. Martin, Madrid, Casa de Velázquez, 2000, pp. 141-156.

KiDw iLl, C., Sannazaro and Arcadia, Londres, Duckworth, 1993.

KorSky, S., Mario Equicola. The Real Courtier, Ginebra, Librairie Droz, 1991. LópE?-Rios, S., "A New Inventory of the Royal Aragonese Library of Naples", Journal of the Warburg and the Courtauld Institutes, 65, 2002, pp. 201-243.

- «Fernando de Aragón», en Diccionario biográfico español, Madrid, Real Academia de la Historia, en prensa.

Marri, M., ed., Rogeri di Pacienza di Nardò, Opere (cod. per. F27), Lecce, Edizioni Milella, 1977.

- "Un carme inedito di Mario Equicola per Isabel del Balzo", en Letteratura comparate. Problemi e metodo. Studi in onore di Ettore Paratore, Bolonia, Patron Editore, 1981, pp. 1319-1328.

Martínez Ortiz, J., "Valencia y la reina de Nápoles", en La corona de Aragón y el Mediterráneo. Aspectos y problemas comunes desde Alfonso el Magnánimo a Fernando el Católico (1416-1516) [IV Congreso de Historia de la Corona de Aragón (Nápoles, 11-15 de abril de 1973)], Zaragoza, Institución Fernando el Católico, 1984, vol. IV, pp. 37-60.

MAXEll SNYDER, H., "Triumphes and pageants at the aragonese court in Naples», Atalaya, 7, 1996 [L'humanisme en Spagne au Xv siecle], pp.4162.

MOREL-Fatio, Alfred, Catalogue des manuscrits espagnols et des manuscrits portugais. Bibliothèque Nationale, París, Imprimerie Nationale, 1892, núm. 134

Pacienza, R. de, Triunfo en terza rima, Perugia, Biblioteca Comunale, ms. F 27.

Parenti, G., Benet Garret detto il Cariteo: profilo di un poeta, Florencia, Olschki, 1993.

Passero, G., Storie in forma di giornali, Nápoles, V. Orsino, 1785.

Percopo, E., "Rimatori napoletani del 400", Giornale storico della Letteratura italiana, VIII, 1886, pp. 318-321

- Le Rime di Benedetto Gareth, Nápoles, s.n., 1892. 
Ruiz-Domènech, J. E., El Gran Capitán. Retrato de una época, Barcelona, Península, 2002.

Salvador Miguel, N., "La instrucción de Isabel la Católica. Los años cruciales (1451-1467)", Arbor, 178, mayo 2004, pp. 107-128.

Sannazaro, J., Opere volgari, ed. A. Mauro, Bari, 1961.

Santoro, M., "Humanism in Naples*, en Renaissance Humanism, ed. Rabil, Philadelphia, University of Pennsylvania Press, vol. I, 1988.

Silvestre BAffi, R., «Di Isabella del Balzo e del suo viaggio attraverso la Puglian, en Studi di Storia Pugliese in onore di Giuseppe Chiarelli, ed. M. Paone, Galatina, Mario Congedo Editore, 1973, pp. 320-351.

Schwartz, R., En busca de liberalidad: music and musicians in the courts of the Spanish nobility, 1470-1640, Ph. D. Dissertation University of Illinois, 2001.

Torre, A. de la,. “Juana de Nápoles. Su venida a España en 1499», en Studi in onore di Ricardo Filangieri, Napoli, L'Arte Tipografica, 1959, vol. II, pp. 245-248.

Toscano, G., «La librairie du Château de Gaillon. Les manuscrits enluminés d'origine italienne acquis par le cardinal Georges d'Amboise», en Léonard de Vinci entre France et Italie "miroir profond et sombre", ed. S. Fabrizio-Costa y J. P. Le Goff, Caen, Presses Universitaires de Caen, 1999, pp. 275-300.

VeCCE, C., Jacopo Sannazaro in Franza: scoperte di codici all'inizio del xvi secolo, Padua, Editrice Antenore, 1988 [=1988a].

- «ll De educatione di Antonio Galateo", Lettere italiane, 40, n 3, 1988, pp. 325-343 [=1988b].

- y P. Tordeur, ed., Antonio De Ferraris (Galateo), De educatione, BruselasLovaina, Peeters Press, 1993.

Volpicella, L., Federico d'Aragona e la fine del regno di Napoli nel mdi, Nápoles, Riccardo Ricciardi Editore, 1908.

- ed., Regis Ferdinandi Primi instructionum liber. Nápoles, 1916.

ZaCchino,V. E., "Il De educatione di Antonio Galateo e i suoi sentimenti antispagnoli", en Atti del congresso internazionale di studi sull'età aragonese (Bari, 15-18 dicembre 1968), Bari, Adriatica Editrice, s.a. 